For citation: Ali, M. M. \& Medhekar, A. (2018). Healthcare Quality of Bangladesh and Outbound Medical Travel to Thailand. Ekonomika regiona [Economy of Region], 14(2), 575-588

doi 10.17059/2018-2-19

JEL: I11, I18, Z32

M. M. Ali ${ }^{\text {a) }}$, A. Medhekar ${ }^{\text {b) }}$

a) Dhaka School of Economics, University of Dhaka (Dhaka, Bangladesh; e-mail: pipulbd@gmail.com)

b) School of Business \& Law, Central Queensland University (Rockhampton, Australia)

\title{
HEALTHCARE QUALITY OF BANGLADESH AND OUTBOUND MEDICAL TRAVEL TO THAILAND ${ }^{1}$
}

The healthcare system in Bangladesh suffers from many shortcomings. This drives not only the affluent and the middle-class, but also the poor Bangladeshi to travel cross-border to India, Thailand, Singapore and Malaysia for medical treatment. In Bangladesh, there are an over-crowded public healthcare system, the paucity of funds, a lack of medical expertise and technology, and few quality private hospitals to service the local high-income population. For this paper, Bangladeshi patients $(n=113)$ who had undergone medical treatment in Thailand during February 2017 to June 2017, completed the survey. Statistical findings suggest that the medical costs are high in Thailand and hiring personal attendants for older patients is expensive. Apart from the language barrier with no interpreting services, the patients are also required to purchase sample medicine from the hospital dispensary at a higher price. On the positive side, the physicians in Thailand were overseas qualified, caring, trustworthy, honest and straightforward while dealing with patients, and had the expertise to provide diagnostic results for several diseases. Results also show that compared to Bangladesh, Thailand has less waiting-time for surgery with state-of-the-art medical facilities, and excellent healthcare service, resulting in an increasing outbound medical travel from Bangladesh. Healthcare policy implications are that the public and private hospitals in Bangladesh need to provide the quality of accredited and timely healthcare to the locals, so that the poor and middle-class Bangladeshi do not have to travel cross-border for healthcare. Unless Bangladesh improves its healthcare system, the outbound medical travel to Thailand and other neighboring countries will continue, and can it dream to develop a medical tourism market to attract foreign patients. Doctors, nurses and lab technicians along with health management personnel must be ethical and corruption free. Improved excellence in healthcare delivery, international accreditation, and elimination of dishonest performs in Bangladeshi healthcare will steadily decrease outbound medical travel by the poor and middle class Bangladeshi, save medical travel costs, medical travel-risk and anxiety of being away from home and relatives, resulting in more and more Bangladeshi patients preferring to trust and use their healthcare system. Future research directions will explore the quality, access and affordability of inclusive healthcare in both public and private hospitals of Bangladesh.

Keywords: Bangladesh, Thailand, medical, travel, public healthcare, quality, accreditation, patient, economic development, region

\section{Introduction}

For any developing country with high population, the healthcare sector is one of the most demanding. It requires more funding as a percentage of GDP, along with availability and equitable access to medical treatment and facilities for the local population. The public healthcare system in Bangladesh is overcrowded, with a paucity of funds, a lack of medical expertise and technology, and few excellent private hospitals exist catering to the local needs [1]. For example, Bangladesh has a branch of famous Apollo Hospitals Group from India, which is an underutilised medical facility. Moreover, Bangladesh Institute of Research

\footnotetext{
${ }^{1}$ ( ) Ali M. M., Medhekar A. Text. 2018.
}

and Rehabilitation in Diabetes, Endocrine and Metabolic Disorders (BIRDEM) does not have the capacity to cater to the needs of a large number of diabetic patients all over the country. Bangladesh is far behind many developing countries in providing adequate healthcare facilities due to funding constraints [2]. The public healthcare system in Bangladesh suffers from the lack of qualified and experienced medical professionals, unnecessary diagnostic tests and outdated medical equipment. Whereas a private health sector is driven by profit motive. This motivates not only the affluent and the middle-class Bangladeshi patients to travel cross-border to Thailand, Singapore and Malaysia for medical surgery, but also the lower income populations to go to India for medical treatment $[1,3,4]$. 
Most of the Bangladeshi people are no longer satisfied with the poor quality of domestic public health system and tend to visit private healthcare services ${ }^{1}$. Government efforts to provide better healthcare services are yet to be realised [5]. With the globalisation of healthcare, many patients from developed countries in Asia are travelling to Thailand, India and Malaysia for obtaining 'first world treatment at third world prices' [1, $6,7,8,9,10,11,12]$. Patients from developed and developing countries compare worldwide healthcare service quality, waiting times, cost, post-surgery care, and search for value in healthcare, relative to their own countries. This has resulted in medical innovation and outsourcing healthcare to low-cost countries $[13,14,15,16]$.

Medical tourism business is a strategy adopted by developing countries for the economic development. It helps to generate revenue from international patients, which translates into output, jobs, and foreign exchange earnings for the destination country, having a multiplier effect on the economy $[1,16,24]$. Issues of economic development and the potential for economic dependency suggest that developed nations in the future might eventually become dependent on developing countries for affordable healthcare provision. At the same time, the developing countries may benefit through the transfer of health technology, pharmaceutical medicines, healthcare innovations, as the foreign exchange revenue from medical travel will help to improve developing countries' healthcare system $[14,16]$. For Bangladeshi middle-class patients after India, Thailand is the second most popular destination for medical treatment and repeat visits. This is due to Thailand's friendly hospitality, the quality of caring healthcare services, world-class medical facilities, cultural affinity and availability of Halal food [17,18, 20, 57]. Bangladeshi with the level of higher income usually travel to developed nations like the USA, UK, Germany and Singapore for surgery [1].

Thailand Board of Investment claimed that in 2016, Thailand had increasing government's expenditure in healthcare and medical tourism. Thai government spends $14 \%$ of its total budget on the healthcare industry, which accounts for $4.6 \%$ of Thailand's GDP. It is the highest amongst the ASEAN countries. Thailand has 53 JCI accredited

\footnotetext{
1 United Nations. (2004). Millennium Project. Millennium Development Goals Needs Assessments: Country Case Studies of Bangladesh, Cambodia, Ghana, Tanzania and Uganda, 1-123. Retrieved from: www.waterfund.go.ke/watersource/ /007.\%20MDG\%20Needs\%20Assessment.pdf (date of access: 1-11- 2017).
}

hospitals $^{2}$. Hospitals maintain electronic medical records of foreign patients. They reply to patient queries by e-mail within shortest possible time. However, in Bangladesh, the quality of healthcare service and facilities comparable to Thailand are not available, due to which Bangladeshi patients choose to travel in large number cross-border for medical treatment [1]. Malaysia and Thailand have a good mixture of elements (medical, tourism and wellness) to be an excellent medical tourism destination while Singapore and India need further development in some of these factors [19].

We have identified four types of inbound medical tourists for Thailand: the dedicated medical tourist, the hesitant, the holidaying, and the opportunistic medical tourist. Bangladeshi patients in this sample even on tourist/visitors visa were all dedicated medical tourists [20]. As discussed by [21], the improving healthcare in Bangladesh requires attention to the 'quality of healthcare service features', which are regularly rated by in-patients in western countries. These features include doctors, nurses, tangibles, and other hospital processes. However, additional organizational and healthcare management issues must also be addressed to improve the overall healthcare system. Further, they commented that in Bangladesh, political influence, corruption at the Ministry of Health and Family Welfare and Directorate of Health, conditions imposed by the Ministry of Establishment and Ministry of Finance in matters of recruitment of medical and non-medical staff, purchase of expensive diagnostics, clinical equipment, related budgetary matters, and interfering nature of the development partners who provide financial assistance are also need to be examined. Failures at all these levels have significant implications for the delivery of healthcare services in Bangladesh [21].

\subsection{Background to Bangladesh Healthcare System}

In the last fourteen years, (2003-04 to 201617) in Bangladesh, the allocation of funds towards the health sector has increased gradually. In the proposed national budget 2017-18, the allocation of funds to healthcare is reduced to Taka, i.e. 13.05 billion from previous year's budget. Total health expenditure in Bangladesh, as a total percentage of GDP in the year 2004 was $2.5 \%$, and gradually

\footnotetext{
${ }^{2}$ JCI. (2017). Joint Commission International Accreditation Standards for Hospitals. Retrieved from http://www.jointcommissioninternational.org/about-jci/jci-accredited-organizations/(Date of access: 12.05.2016).
} 
increase to $3.7 \%$ in 2013 and fell to $2.8 \%$ in $2014^{1}$. In 2014, per-capita health expenditure increased to $\$ 27$, from $\$ 16$ in 2007 . However, governments share in health expenditure has declined from $27 \%$ to $23 \%$, which is very low for achieving the objective of universal healthcare, resulting in an increase in the out-of-pocket expenditure of $63 \%$ for the patients. The people of Bangladesh are concerned about the high out-of-pocket payment for health, and there is a need for reforms into healthcare finance scheme [22]. However, from the supply side, the country is still not prepared to provide benchmark quality and access to affordable public healthcare for everyone. There are numerous medical schools and hospitals in Bangladesh, but their quality of health service is questionable $[1,21,23]$. Best doctors migrate to overseas countries for better working conditions, medical facilities and remuneration ${ }^{2}$. The factors that motivated Bangladeshi to travel to India for medical treatment are the following: low cost of surgery, qualified experienced doctors, quality of nursing care, non-availability of treatment in Bangladesh, and state of the art medical facilities and treatment in India [24].

To overcome quality in access to universal healthcare, the World Bank has promised to provide US\$515 million to Bangladesh to improve health, nutrition and population services under the 4th health sector programme, costing US $\$ 14.7$ billion $^{3}$. The programme will strengthen the country's health system, cover essential primary healthcare services and enhance equity through focussed service improvements in Sylhet and Chittagong divisions where key health indicators are below national averages. The project will also work to improve neonatal mortality rate, maternal mortality ratio, total fertility rate, and prevalence of stunting among under the age of five children, hypertension among adults and increase the total health expenditure financed from public sector ${ }^{4}$. The aim of this program under the Health and Family Welfare Ministry is to ensure quality and equitable access to healthcare services for all Bangladeshi citizens. Bangladesh has made remarkable achievements in health-re-

\footnotetext{
${ }^{1}$ World Bank. (2003). Private sector assessment for health, nutrition and population in Bangladesh. Report No. 27005-BD, 6-7. Washington, DC: World Bank. Retrieved from http://documents.worldbank.org/curated/en/(Date of access 25-4-2017). ${ }^{2}$ Ibid.

${ }^{3}$ The Bangladesh Chronicle. (2017). Government World Bank $\$ 515 \mathrm{~m}$ loan deal for health sector, 28 August 2017. Retrieved from: http://bangladeshchronicle.net/2017/08/28/ (date of access: 12-11-2017).

${ }^{4}$ Ibid.
}

lated Millennium Development Goals (MDGs), though in the case of Sustainable Development Goal-3 (ensure healthy lives and promote well-being for all at all ages) has not been fully achieved. Prime Minister Sheikh Hasina received the UNMDG Award in 2010 for success in reduction of under-five mortality. In 2011, Bangladesh received 'Digital Health for Digital Development', a SouthSouth Award for successful attainment of MDG-4 \& MDG-5, as the Government of Bangladesh recognizes health as an integral part of development process. However, there is a lack of political will, in case of actual allocation of funds and implementing health-related projects and programs ${ }^{5}$. SDG3 refers to ensure healthy living and promote wellbeing for all, at all ages ${ }^{6}$. Knowledge about hygiene, language and cleanliness, medical equipment and tests, meals, needs and caring, attractive and punctual, examination and skills, admission process and professionally dressed have emerged important factors for determining the quality of the private healthcare services of Bangladesh [25].

Improvements in the health of the Bangladeshi population would translate into higher productivity, incomes, economic growth, and accelerated poverty reduction. However, more needs to be done to achieve SDG3, universal primary, secondary and tertiary, access to reliable quality of healthcare along with the availability of healthcare facilities, diagnostic services at an affordable price, especially for the poor people living in rural and remote villages as well as for the urban poor. In Bangladesh, pathological and diagnostic tests are not reliable, due to the poor quality of healthcare facility and medical technology, long waiting time, unavailability of super-specialty, and corruption, as doctors often take a commission for different unnecessary diagnostic tests as reported in the media [1, 17, 18, 23]. Given the poor healthcare quality, health-conscious Bangladeshi's demand for quality healthcare is on the rise, and more and more patients are travelling abroad to seek quality in healthcare. Building on the previous research, a research gap was identified regarding the reasons for medical travel to Thailand, where it was found that Bangladeshi crossed a border for high-end care, because of the poor quality of healthcare services, diagnostic clinics, lack medical expertise, surgical speciality, and post-surgery care [1, 17, 23]. In Bangladesh, currently, there are 31 Government medical colleges and 68 pri-

\footnotetext{
${ }^{5}$ World Health Statistics. (2017). Retrieved from: www.who.int/ gho/publications/world_health_statistics2016_Chapter6.pdf (date of access: 12-11-2017).

${ }^{6}$ Retrieved from: http://www.who.int/sdg/targets/en/(viewed (date of access: 10-11-2017).
} 
vate medical colleges. Furthermore, there is an urgent need that the quality of healthcare services offered at Bangabandhu Sheikh Mujib Medical University (Formerly Institute of Postgraduate Medical Research (IPGMR), which was established in December 1965), and Dhaka Medical College and Hospital that was established in the year 1946, will be improved. The government in Bangladesh, recently, decided to set up two medical universities through Chittagong Medical University Act, 2015 and Rajshahi Medical University Act, 2015, to meet the shortage of medical facilities and medical doctors and nurses. In the case of in-patient treatment in a government facility in Bangladesh, especially if surgical intervention is required, the households have to incur a huge amount as outof-pocket expenditures on medicines, diagnostic tests and other related items. To meet the hospitalisation expenses, many households have to borrow money and even liquidate their assets [5].

A small case of unethical practices in Bangladesh, which is a normal phenomenon is quoted: "Unfortunately with the few exceptions they are indulged in immoral activities and unethical practices of all sorts. I think it is not too late to rectify ourselves now. Malpractices of all sorts have engulfed the physicians of all categories and money appears as the single most important driving factor. Money should not be the only factor for our profession. Cesarean operation is a lifesaving method for mother and baby for selective and complicated labor. It is popular in the West. However, in Bangladesh, it is different. When this procedure was first available in our country several decades ago, hardly $10 \%$ labor was due to it. Now around $50 \%$ (varies $40 \%$ to $95 \%$ ) labors are due to it across the country and in majority cases injudiciously. It becomes the easiest method of earning a lot of money within shortest possible time! If we become an exploiter instead of a perfect technical person, how can we be able to protect the interest of a patient? Cases of gross negligence on the part of physicians are being reported in the paper now and then. One of my known patient decided to deliver their baby by Cesarean section. He managed to get the best anesthesiologist and gynecologist. Patient started muscle twitching on the operation table during later part of operation. On inquiry, it was found that Oxygen cylinder ran out of oxygen! In addition, the anesthetist was found upstairs in computer game! By this time patient incurred irreparable brain damage. Then she was transferred from Dhaka to Singapore, attended by both the British and the American specialists. Now she is unconscious, has been bed-ridden for last one and a half decades, on life-sav- ing measures." An overwhelming number of the patients and their attendants also faced negligence, of different types in the hospital services in Bangladesh [26].

The key aim of this paper is to explore the reasons for outbound medical travel from Bangladesh to Thailand for surgery, due to the low quality of healthcare in Bangladesh. This paper is structured as follows. First part covers introduction and background to the healthcare system of Bangladesh. Followed by a literature review on medical travel to Thailand. Part three deals with research methodology, justification and research hypothesis. Policy implications for healthcare discussed in part four; followed by conclusions and future research directions.

\section{Literature Review}

\subsection{Trade in Healthcare Services and Medical Travel}

Cross-border trade in healthcare services of developing countries is expanding, becoming more competitive, and creating new dimensions of the globalization of healthcare, as the new niche of the medical market for global healthcare [16, 27, $28,29,30]$. In Canada, supporters of medical tourism argue that medical travel reduces waiting list at home and improves access to care for citizens who cannot afford to travel abroad for surgery. Supporters of medical tourism note that internationally accredited private healthcare facilities are located around the world and especially in Asia. South American countries provide international and comparable quality of medical surgeries [30, 31, 32]. There is a positive impact of medical tourism in the developing countries, which also raises many ethical and moral questions. Growing healthcare globalization due to medical travel has its costs and benefits for the patient who travel overseas for surgery. Such treatments may include dental, heart, orthopedic and bariatric surgery, reproductive services and liver or kidney transplantation $[6,14,32]$.

Medical tourism can bring economic benefits to developing countries, and additional foreign resources for investment in healthcare [16, 33]. However, unless medical travel is accredited, managed, and regulated, the financial benefits of medical tourism for health systems may come at the expense of access to and use of health services by the local population. There is a lack of systematic data concerning international health services

1 Retrieved from: http://www.pnhp.org/news/2010/october/ lessons-from-bangladesh (date of access: 15-10-2017). 
trade, in the case of individual modes of delivery and advantage to destination countries, resulting from medical tourism [34].

Despite being part of an increasingly global medical industry, most of the medical travel is cross-border and diasporic, mainly linked to and parallel with the tourism industry, as foreign medical tourists also use tourism services, such as, book hotels, accommodation, shopping, and some sightseeing [35, 36]. Intermediaries such as medical tourism travel agents and facilitators also play a key role in connecting patients to hospitals, airlines and hotels. In Bangladesh, family and friends play a significant role to inform the potential patients by 'Word of Mouth' along with internet that plays a secondary role in spreading the information in Bangladesh. Healthcare quality and availability of care are key influences on medical travel behaviour, alongside economic and cultural factors for Bangladeshi patients. National health and economic statistics can assist in developing metrics of public and private revenues, benefits, and aggregate welfare gains from medical tourism [36, 37]. Therefore, detailed developing country specific studies are required to ascertain the distributional impact of net economic health gains and losses to the economy from medical travel. Some measure of patient flows could be estimated from data collected by medical tourism facilitators or destination country healthcare facilities, and from government medical-visa category. However, such information is confidential and difficult to obtain by the researchers.

\subsection{Thailand as a Medical Destination for Bangladeshi}

Thailand is a popular tourist place as well as a top medical tourism destination for the patients. Medical tourists are drawn to Thailand from all parts of the world because of the excellent quality of healthcare, accredited hospitals by JCI, affordable pricing and tourism attractions $[20,33$, $38,39,40]$. Health screening packages in Thailand are bundled with hotel, tourism and travel packages, which is half the cost of Singapore [41]. Thailand faces credibility concerns when it comes to complex higher-end surgical treatment. Bumrungrad Hospital, for instance, had to market and promote itself as the US, JCI accredited hospital to avoid the perception of low-quality services. In Thailand, quality considerations are given top priority by private hospitals regardless of the type of treatment sought. Certain types of medical procedures availability and quality influences the decision-making processes of medical tourists when they are looking for medical service providers [20,
$42,43]$. Bioethics includes medical ethics, environmental ethics, legal ethics, business ethics and ethics in human rights and politics including matters of crisis management. Corruption, nepotism, selfishness, misconduct and malpractice are becoming the common phenomena in Bangladesh healthcare [44], causing Bangladeshi to travel to Thailand.

In Thailand, doctors are courteous, patients are dealt with quickly and efficiently in a friendly manner, and do not display the authoritarian "doctor's gaze," thereby making clients feel comfortable like guests than foreign patients [45]. This makes a visit to an overseas hospital a positive experience and reduces fear which is associated with hospital visits when suffering from serious disease. In the case of Japanese outbound medical tourists to Thailand, some elderly middle income Japanese stay for long, in spite of high medical costs, as their incomes are relatively high compared with the average Thai or Bangladeshi patients, with no health insurance and out-ofpocket medical expenses, in addition to travel and accommodation costs [46].

Medical tourism has led to the shortage of staff and high healthcare costs for local Thai population, for physicians, dentists and nurses [47]. [48], identified that the strengths of Thailand's healthcare service providers and highlights a number of problems that may reduce the growth opportunity of this industry. These include a lack of practical government policies with regard to medical tourism and of other supporting medical regulations, a lack of organization as a cooperation center aimed at promoting the medical tourism industry as a whole, remaining low awareness of the opportunities presented by the industry among potential foreign patients, and a shortage of doctors and qualified medical staff [48]. Thailand's main advantages are its high quality of medical professionals, no waiting-time, affordable healthcare costs, state-of-the-art healthcare facilities and a hospitable and service-minded culture [40]. Besides, Thailand has traditionally been a popular global tourist destination and specialises in niche areas for cosmetic, dental, reproductive and wellness tourism packages.

Thailand receives a large number of inbound medical tourists from western countries and cross-border in Asia. Private hospitals specially cater to foreign medical tourists and are able to cope influx of high and low season medical tourists from all over the world [50]. Major hospitals in Thailand are capable to meet the growing demand for medical tourists from Asia and abroad during high season. Medical travellers search for 
internal and external sources of information [50, 52] or contact the medical service providers/hospitals through online internet appointment [51]. Internet has become a platform for hospitals, medical travel agents and medical tour facilitators to promote their healthcare services to search for hospital and doctor, based on patient's medical problems in many countries [34]. In Thailand, medical information system works on cloud computing for cosmetic clinic management. Cloud computing was developed by the cooperation of researchers, doctors and network service providers, providing easy access to transfer patient data between the physician and patient $[53,54]$. Social media is also utilized to create opportunities for medical travel market for patients and doctors to share their ideas, needs and requirements in the field of health tourism.

Differences exist between hospital websites in India, Singapore, Malaysia, and Thailand, pointing to the need for hospital managers to improve their hospitals home page so that patients can easily navigate and hospitals can cater to patients needs from different countries, as their healthcare needs, motivation factors for travel and expectations vary [55]. Hospital settings catering for medical patients present highly complex cross-cultural interactions between medical staff and patients, but also between patients and other patients. This has ramifications for notions of 'cultural competence 'and 'transcultural nursing' in medical care, which strive to provide services to patients of diverse values and religious beliefs by paying special attention to their social, cultural, diet and linguistic needs [56]. Health tourism facilities and medical and administrative staff have to be sensitive to patients from different cultural and religious backgrounds such as medical travellers from Islamic countries [18].

To improve short-term medical volunteer work by the medical professionals, it was necessary to coordinate with and respect local healthcare providers and their communities, as insufficient understanding of the country's existing healthcare resources and needs may result in perceived harm to the recipient community [57]. Therefore, it is essential that the Tourism Authority of Thailand support studying of medical tourist behavior and medical tourist needs from different countries and religious backgrounds. In doing this, they can access the tourism resources of the Tourism Authority of Thailand (TAT). Further, TAT travel agencies and spa businesses post detailed information on the internet regarding the quality of healthcare services provided by famous hospitals such as Bangkok Hospital and Bumrungrad
Hospital, which are popular with foreign medical tourists. Moreover, TAT can emphasise on the role played by health tourism facilitators and the medical standards in Thailand, and compare them to that of the USA or Switzerland [58]. TAT has started to promote medical tourism in 2004, developed a detailed medical tourism website that highlights many of the most popular treatments available including dental works, dermatology, and cosmetic surgery as well as listing reputed hospitals, making it easy for potential visitors to decide on a procedure [54]. Therefore, the cross-border healthcare sector is entwined with a demand for additional services for foreign patients whose expectations are high, in comparison to the domestic demand for healthcare from locals [1].

Bagadeshi patients are more likely to be motivated to go to a chosen country such as Thailand because they have a positive perception towards the quality of medical service providers in Thailand. Therefore, patients with higher perception towards the image of the chosen destination as Thailand tend to perceive the higher quality of medical procedures at Thai medical facilities [59]. Medical tourists from Bangladesh have a positive perception of service quality of medical facilities of Thailand and India, giving the shorter waiting-time and affordable quality. Therefore, they are more likely to travel for medical reasons and be satisfied with the healthcare services. The literature review is based on inbound medical tourism to Thailand from different countries. However, these studies did not consider the push factors for outbound Bangladeshi patients to Thailand due to the poor quality of Bangladeshi healthcare provision. The aim of this chapter is to focus on the reasons for Bangladeshi patients to travel to Thailand, as one of the members of BIMSTEC countries. The objective of this research is to examine the association between four hypothesis stated in Table 2 along with findings.

\section{Methodology and Findings}

\subsection{Participants}

This study is based on the quantitative survey data, which were collected from Bangladeshi medical travellers who had all undergone medical treatment in Thailand. Purposive sampling and snowball technique were used, with the condition that patients went to Thailand for medical treatment, to select a sample of respondents. Survey data were collected during February 2017 to June 2017 from 113 Bangladeshi patients, post-surgery, who had experienced medical tourism to Thailand. 
However, out of these 113 patients, the data of 43 Bangladeshi respondents were collected in Thailand from various hospitals in Bangkok. The remaining 70 surveys were collected from Dhaka and Chittagong metropolitan area. From this sample, 43 Bangladeshi patients, only two officially travelled on Thai medical-visa and other 41 travelled to Thailand as tourists to avoid the complications of getting medical-visa. The main purpose of all of the dedicated medical patients was medical treatment and not tourism.

The study also took in-depth one to one qualitative interview of the patients to crosscheck and validate their view, The details of it are not presented in this chapter. Statistical analysis techniques using SPSS version 22 was used for reliability and validity tests. Factor analysis is based on eight factors. (i) Deliverable services of health sector in Bangladesh, (ii) Better quality of healthcare services in Bangladesh, (iii) Expertise of doctor/nurses, (iv) Overall hospital's treatment environment at Thailand, (v) Cost savings at Thailand, (vi) Availability of Halal food in Thailand, (vii) Affordable and caring healthcare service in Thailand, (viii) Medical care along with some relaxation in Thailand, and (ix) Less waiting time for appointments and surgery.

\subsection{Findings}

In the model, medical treatment in Thailand is considered as dependent variable while independent variables are satisfaction level, cost of treatment and healthcare expectation in Thailand. The study has following binary logistic regression model: MTT $=f(C T$, ST, EX). Where, MTT $=$ Medical Treatment in Thailand; $\mathrm{CT}=$ Cost of treatment; $\mathrm{ST}=$ satisfaction $; \mathrm{EX}=$ Expectation. From Table 1, Medical Treatment in Thailand is positively related to satisfaction level, and significant at $1 \%$ level of significance and negatively related to the cost of treatment at $5 \%$ level of significance. However, coefficient and expectation levels are insignificant. Mcfadden $R$-squared $=(.6151)$. The likelihood ratio test value is 101.3121 . The null hypothesis is not fully rejected as the expectation is insignificant, but other two independent variables are significant. The findings conclude that Medical Treatment in Thailand is related to Cost of Treatment and Satisfaction Level is significant, but Expectation is insignificant.

Treatment in Thailand as dependent variable while independent variables are satisfaction level and the cost of treatment in Thailand.

Here satisfaction level is significant at $1 \%$ level while the cost of treatment is significant at $5 \%$ level of significance.

Table 1

Estimated Result of Logistic Regression

\begin{tabular}{|l|c|c|c|c|}
\hline \multicolumn{5}{|c|}{ Dependent Variable: Medical Treatment in Thailand } \\
\hline & C & CT & ST & EX \\
\hline Coefficient & -0.827 & -0.91 & 1.611 & 0.78 \\
\hline Std. Errors & 1.524 & $.399^{* *}$ & $.516^{* *}$ & 1.754 \\
\hline $\begin{array}{l}\text { McFadden } \\
\text { R-squared }\end{array}$ & 0.615 & LR & statistic & 101.312 \\
\hline Total & & 113 & & \\
\hline
\end{tabular}

Note: ${ }^{* * *}=1 \%$ level of satisfaction; ${ }^{* *}=5 \%$ level of satisfaction. (Source: Estimated results based on Data obtained from the survey).

The following hypothesis in Table 2 was tested with Chi-square estimates.

Table 3 shows association between numbers of times Bangladeshi patients visited Thailand for the purpose of medical treatment and deliverable services quality of healthcare in Bangladesh.

Nearly $13.9 \%$ of patient have experienced the highest quality of healthcare service in Bangladesh, high (11.1\%), moderate services (18.1\%), low (33.3), and $23.6 \%$ experienced lowest healthcare service quality. Because of which they travelled abroad to Thailand for medical reasons. In addition, $2.4 \%$ experienced highest healthcare services quality in hospitals of Bangladesh, high (12.2\%), moderate (4.9\%), and low services $(75.6 \%)$. Patients $(4.9 \%)$ who experienced the lowest quality of healthcare services in Bangladesh travelled more than once time to Thailand for medical treatment. However, the results indicate that there was a relationship between going to Thailand for medical treatment and deliverable services of Bangladesh, $\left(\chi^{2}=22.00 ; P<.000\right)$, and the alternative hypothesis (H1) is accepted. This means that relationship between numbers of times Bangladeshi patients visited Thailand for medical treatment purpose $\rightarrow$ because the deliverable services of healthcare sector of Bangladesh were not excellent.

Table 4 shows the association with numbers of times Bangladeshi patients visited Thailand for medical treatment purpose and quality of healthcare in Thailand.

Data in Table 4 explains associations with numbers of times Bangladeshi patients visited Thailand for medical treatment purpose. From Table 4, it can be observed that $5.6 \%$ of respondents travelled only once to Thailand because they received the highest level of better quality of services in their home country Bangladesh. Further, the data show that patients travelled once to Thailand for medical purposes, because nearly $12.5 \%$ experienced a high quality of healthcare services in Bangladesh; moderate (4.2\%), low 
Table2

Hypothesis

\begin{tabular}{|c|c|c|c|}
\hline Hypothesis & Reason & Results were given & Findings of Hypothesis \\
\hline $\begin{array}{l}\text { Association between numbers of times } \\
\text { Bangladeshi patients visited Thailand } \\
\text { for medical treatment purpose and } \\
\text { deliverable services } \\
\text { Quality of healthcare in Bangladesh }\end{array}$ & $\begin{array}{l}\text { the deliverable services of } \\
\text { healthcare sector of Bangladesh } \\
\text { was not excellent }\end{array}$ & Table:3 & Accepted \\
\hline $\begin{array}{l}\text { Association between numbers of times } \\
\text { Bangladeshi patients visited Thailand } \\
\text { for medical treatment purpose and } \\
\text { quality of healthcare at Thailand }\end{array}$ & $\begin{array}{l}\text { Related between numbers of } \\
\text { times Bangladeshi patients } \\
\text { visited Thailand for } \\
\text { medical treatment purpose and } \\
\text { quality of healthcare at Thailand }\end{array}$ & Table: 4 & Accepted \\
\hline $\begin{array}{l}\text { Association between different sources } \\
\text { of medical travel information that is } \\
\text { easily available and patient satisfaction }\end{array}$ & Cost savings in Thailand & Table:5 & Accepted \\
\hline $\begin{array}{l}\text { Association between the numbers of } \\
\text { patients went to Thailand for medical } \\
\text { treatment purpose and expertise } \\
\text { of Doctor-nurses and overall poor } \\
\text { hospital environment and treatment in } \\
\text { Bangladesh }\end{array}$ & $\begin{array}{l}\text { The expertise of Doctor-Nurses } \\
\text { and overall very poor quality of } \\
\text { Hospital's healthcare treatment } \\
\text { environment in Bangladesh }\end{array}$ & Table:6 & Accepted \\
\hline
\end{tabular}

(Source: Prepared by the authors').

Table 3

\begin{tabular}{|l|c|c|c|c|c|c|c|}
\hline \multirow{2}{*}{ Number of visits to Thailand } & \multicolumn{3}{|c|}{ Deliverable services in Bangladesh } & \multirow{2}{*}{ Total } \\
\cline { 2 - 8 } & & Highest & High & Moderate & Low & Lowest & \\
\hline \multirow{2}{*}{ Once } & Number & 10 & 8 & 13 & 24 & 17 & 72 \\
\cline { 2 - 9 } & $\%$ & 13.90 & 11.10 & 18.10 & 33.30 & 23.60 & 100.00 \\
\hline \multirow{2}{*}{ More than once } & Number & 1 & 5 & 2 & 31 & 2 & 41 \\
\hline \multirow{2}{*}{ Total } & $\%$ & 2.40 & 12.20 & 4.90 & 75.60 & 4.90 & 100.00 \\
\hline Pearson $X^{2}=22.00_{(4)} P<.000$ & Number & 11 & 13 & 15 & 55 & 19 & 113 \\
\cline { 2 - 9 }$n$
\end{tabular}

(Source: Estimated results based on Data obtained from the survey).

Table 4

\begin{tabular}{|l|c|c|c|c|c|c|c|}
\hline \multicolumn{2}{|c|}{ Number of visits to Thailand } & \multicolumn{5}{c|}{ Better quality of healthcare } & \multirow{2}{*}{ Total } \\
\cline { 2 - 9 } & Highest & High & Moderate & Low & Lowest & \\
\hline \multirow{2}{*}{ Once } & Number & 4 & 9 & 3 & 31 & 25 & 72 \\
\cline { 2 - 9 } & $\%$ & 5.60 & 12.50 & 4.20 & 43.10 & 34.70 & 100.00 \\
\hline \multirow{2}{*}{ More than once } & Count & 1 & 2 & 8 & 12 & 18 & 41 \\
\cline { 2 - 9 } & $\%$ & 2.40 & 4.90 & 19.50 & 29.30 & 43.90 & 100.00 \\
\hline \multirow{2}{*}{ Total } & Count & 5 & 11 & 11 & 43 & 43 & 113 \\
\cline { 2 - 9 } & $\%$ & 4.40 & 9.70 & 9.70 & 38.10 & 38.10 & 100.00 \\
\hline Pearson $X^{2}=10.34(4) \mathrm{P}<.035$ & & & & & & & \\
\hline
\end{tabular}

(Source: Estimated results based on Data obtained from the survey).

quality of healthcare (43.1\%) and lowest quality of healthcare services in Bangladesh was received by $34.7 \%$ of patients.

Further, as Bangladeshi patients who did not receive better quality of services in their home country travelled more than once time to Thailand for medical treatment. Those who travelled more than once to Thailand for medical services at the highest level were (2.4\%), high (4.9\%), moderate (19.5\%), low (29.3\%) and at the lowest level were $(43.9 \%)$. However, the data indicates that there is a relation between going to Thailand for med- 
Table 5

\begin{tabular}{|l|c|c|c|c|c|c|}
\hline \multicolumn{2}{|c|}{$\begin{array}{c}\text { Source of getting information on medical } \\
\text { travel/treatment }\end{array}$} & \multicolumn{5}{c|}{ Overall Patient Satisfaction } \\
\cline { 3 - 8 } & $\begin{array}{c}\text { Highest } \\
\text { Cost saving }\end{array}$ & $\begin{array}{c}\text { High-cost } \\
\text { saving }\end{array}$ & $\begin{array}{c}\text { Moderate } \\
\text { cost saving }\end{array}$ & $\begin{array}{c}\text { Low-cost } \\
\text { saving }\end{array}$ & $\begin{array}{c}\text { Lowest cost } \\
\text { saving }\end{array}$ \\
\hline \multirow{2}{*}{ Once } & Count & 8 & 9 & 7 & 26 & 22 \\
\cline { 2 - 8 } & $\%$ & 11.10 & 12.50 & 9.70 & 36.10 & 36.60 \\
\hline \multirow{2}{*}{ More than once } & Count & 0 & 3 & 3 & 32 & 3 \\
\cline { 2 - 8 } & $\%$ & 0.00 & 7.30 & 7.30 & 78.00 & 7.30 \\
\hline \multirow{2}{*}{ Total } & Count & 8 & 12 & 10 & 58 & 25 \\
\hline Pearson $X^{2}=0.715_{(4)} P<.000$ & $\%$ & 7.10 & 10.60 & 8.80 & 51.30 & 22.10 \\
\hline
\end{tabular}

(Source: Estimated results based on Data obtained from the survey).

Table 6

\begin{tabular}{|c|c|c|c|c|c|c|c|}
\hline \multirow{2}{*}{\multicolumn{2}{|c|}{$\begin{array}{l}\text { Number of times patients went to Thailand } \\
\text { for medical treatment }\end{array}$}} & \multicolumn{5}{|c|}{$\begin{array}{l}\text { The expertise of doctor-nurses and overall poor hospital } \\
\text { environment and treatment in Bangladesh }\end{array}$} & \multirow{3}{*}{$\begin{array}{c}\text { Total } \\
72 \\
\end{array}$} \\
\hline & & \multirow{2}{*}{ Highest } & \multirow{2}{*}{$\begin{array}{c}\text { High } \\
13\end{array}$} & \multirow{2}{*}{$\begin{array}{c}\text { Moderate } \\
3\end{array}$} & \multirow{2}{*}{$\begin{array}{c}\text { Low } \\
23\end{array}$} & \multirow{2}{*}{$\begin{array}{c}\text { Lowest } \\
32\end{array}$} & \\
\hline Once & Count & & & & & & \\
\hline & $\%$ & 1.40 & 18.10 & 4.20 & 31.90 & 44.40 & 100.00 \\
\hline \multirow[t]{2}{*}{ More than once } & Count & 1 & 5 & 3 & 25 & 7 & 41 \\
\hline & $\%$ & 2.40 & 12.20 & 61.00 & 17.10 & 7.30 & 100.00 \\
\hline \multirow[t]{2}{*}{ Total } & Count & 2 & 18 & 48 & 39 & 6 & 113 \\
\hline & $\%$ & 1.80 & 15.90 & 5.30 & 42.50 & 34.50 & 100.00 \\
\hline Pearson $X^{2}=12.068_{(4)} P<.017$ & & & & & & & \\
\hline
\end{tabular}

(Source: Estimated results based on Data obtained from the survey).

ical treatment and better quality of healthcare of Bangladesh, where $\left(\chi^{2}=10.34(4) ; P<.035\right)$, and the alternative hypothesis (H2) is accepted. There is a positive association between the number of times of visits to Thailand for medical treatment $\rightarrow$ due to excellent healthcare service quality in Thailand compared to Bangladesh.

Table 5 shows both the association between different sources of medical travel information that is easily available and patient satisfaction

Data in Table 5 indicate that respondents, who searched for various sources of information before travelling to Thailand for medical treatment, had significant cost-savings. For example, nearly $11.1 \%$ of respondents had highest cost savings, $12.5 \%$ - high-cost savings, moderate cost-savings - (9.7\%), low cost-savings - (36.1\%) and $30.6 \%$ had the lowest-wings. In addition, the results also indicate that $7.3 \%$ of respondents had highest and moderate cost-savings as they visited Thailand twice for medical treatment. Further, $78.0 \%$ respondents had highest cost-savings, and $7.3 \%$ of respondents had lowest-cost savings because they gathered information from various sources regarding medical travel to Thailand. Results indicate that there was a significant relationship between getting information for the med- ical purpose from many sources and medical cost savings in Thailand $\left(\chi^{2}=20.715 ; P<.000\right)$, and the alternative hypothesis (H3) is accepted. Therefore, there is a positive association between different sources of medical travel information that is easily available $\rightarrow$ due to which the cost-savings in Thailand is possible.

Results in Table 6 indicate the number of times patients travelled to Thailand for medical treatment due to the low expertise of doctor-nurses and overall poor hospital treatment and the environment in Bangladesh. The respondents who travelled to Thailand only once, considered treatment in Bangladesh at highest level (1.4\%), high level - (18.1\%), moderate - (14.2\%), low level (31.9\%) and lowest level - (44.4\%) due to the low expertise of medical professionals, hospital treatment and environment in Bangladesh.

Table 6 shows an association between the number of patients went to Thailand for medical treatment purpose and expertise of Doctor-nurses and overall poor hospital environment and treatment in Bangladesh.

In addition, patents who travelled to Thailand twice due to the low expertise of medical professionals and poor hospital treatment and the environment was considered highest (2.4\%), high 
Table 7

Perception about Thailand by Bangladeshi patients

\begin{tabular}{|c|c|c|}
\hline Factor Description & Communalities & Component- 1 \\
\hline $\begin{array}{l}\text { Deliverable services } \\
\text { of Bangladesh health } \\
\text { sector }\end{array}$ & 0.577 & 0.744 \\
\hline $\begin{array}{l}\text { Better quality of } \\
\text { services at Bangladesh }\end{array}$ & 0.569 & -0.702 \\
\hline $\begin{array}{l}\text { The expertise of } \\
\text { doctor-nurses and } \\
\text { overall hospital } \\
\text { treatment }\end{array}$ & 0.506 & 0.201 \\
\hline Cost saving & 0.593 & -0.197 \\
\hline & & Component -2 \\
\hline $\begin{array}{l}\text { Availability of Halal } \\
\text { food in Thailand }\end{array}$ & 0.577 & 0.125 \\
\hline $\begin{array}{l}\text { Affordable and caring } \\
\text { healthcare in Thailand }\end{array}$ & 0.569 & 0.117 \\
\hline $\begin{array}{l}\text { Medical care along } \\
\text { with some rest and } \\
\text { relaxation in Thailand }\end{array}$ & 0.577 & 0.743 \\
\hline $\begin{array}{l}\text { Least waiting-time for } \\
\text { medical treatment }\end{array}$ & 0.593 & 0.734 \\
\hline \multicolumn{3}{|c|}{$\begin{array}{l}\text { Kaiser-Meyer-Olkin (KMO) Measure of Sampling } \\
\text { Adequacy = 0.493; Cronbach Alpha }=0.621\end{array}$} \\
\hline \multicolumn{3}{|c|}{$\begin{array}{l}\text { Bartlett's Test of Sphericity - Chi-square } X^{2} / d f 3.528(6): \\
\mathrm{P}<0.740\end{array}$} \\
\hline \multicolumn{3}{|c|}{ Variance: Comp-1=28.129\%; Comp-2: $28.006 \%$} \\
\hline
\end{tabular}

(Source: Estimated results based on Data obtained from the survey).

level (12.2\%), moderate (61 \%), low (17.10 \%) and lowest $(7.30 \%)$ ). Table 6 shows a significant relationship between the number of patients went to Thailand for medical treatment, due to the low expertise of medical staff and overall very poor quality of hospitals' healthcare treatment environment in Bangladesh $\left(\chi^{2}=12.068 ; P<.017\right)$, and the alternative hypothesis (H4) is accepted. The results conclude that the number of times the patients visited Thailand for medical treatment purpose $\rightarrow$ because of the low expertise of doctor-nurses and overall poor hospitals' healthcare treatment environment, which is worst in Bangladesh.

Table 7 reports that the KMO measure of sampling adequacy is greater than 0.49 , the sample size was adequate for factor analysis. The study eight principal components with an Eigenvalue $>1$ is explained by $28 \%$ of four components and rest four components were not responsive. The Bartlett's Test of Sphericity was not statistically significant $\left(\chi^{2}=3.528, P<0.740\right)$, which indicated that variances across groups against the alternative that variances were equal for at least two groups. Cronbach's alpha was satisfactory 0.621 , which signified moderate results. The average communality for the variables was calculated as
0.56 , which was also satisfactory given the sample size for this study.

\section{Discussion and Implications}

From the results, we can conclude that outbound cross-border medical travel from Bangladesh to its neighboring countries will continue to increase. This is mainly because of the poor quality of healthcare services and facilities, unreliable pathological and diagnostic reports, outdated medical technology, a lack of medical super-specialties and expertise, corruption - where doctors often take a commission for unnecessary diagnostic tests - that is regularly reported in the newspapers. After India, Thailand is the next destination for repeat visits by Bangladeshi patients mainly because of the country's friendly hospitality, quality of caring healthcare services, world standard medical facilities, language, cultural affinity and availability of Halal food mentioned by the sample of patients.

In the case of Thailand, in the open-ended questions, most of the patients suggested that additional English speaking medical and non-medical staff in Thailand are required such as interpreters. Further availability of affordable attendants for old patients, might encourage repeat visits by Bangladeshi to Thailand. Patients further suggested that accredited hospitals with foreign joint venture can be established in Bangladesh through Government-to-Government protocol, as a part of Bay of Bengal Initiative for Multi-Sectoral Technical and Economic Cooperation (BIMSTEC), which will encourage Bangladeshi to use quality domestic healthcare facilities. Bangladesh has only one-Apollo as JCI accredited hospital compared to 54 in Thailand [19]. Further, some patients commented that recent decision by the Indian government to ban cow-meat creates a negative image of India. However, India is still the popular medical travel destination due to strong cultural affinity, language, food and common historical heritage, being part of one country pre-1947 [49]. The following Table 8 provides other countries, which the sample of 113 Bangladeshi patients visited for medical tourism before Thailand.

In Bangladesh, neither public nor private hospitals follow any type of self-assessment and external quality accreditation process to accurately assess their level of performance in relation to established health quality standards and to implement ways for continuous quality improvement and accreditation healthcare facilities and medical professional staff qualifications [19]. Bangladesh is not equipped to provide quality of healthcare services to its local population, due to a lack of med- 
Table 8

Popular Countries as Medical Travel Destinations

\begin{tabular}{|l|c|}
\hline Name of the country & No. of respondents \\
\hline India & 42 \\
\hline Singapore & 23 \\
\hline Malaysia & 11 \\
\hline Sri Lanka & 9 \\
\hline Others & 28 \\
\hline Total & 113 \\
\hline
\end{tabular}

(Source: Study Data).

ical equipment, super-specialty and state-of-theart medical technology along with especially unethical behavior and rampant corrupt practices of medical practitioners and profit motive objectives of the owners of private hospitals, putting patient clinical and medical safety at risk in Bangladesh.

Thailand as a medical travel destination for Bangladeshi patients may occupy the first position in the future. This is because in India, as per new medical travel regulation, without medical tourist-visa, accredited private hospitals do not admit foreign patients. Further, organ donation and transplantation laws are regulated in India to protect the vulnerable donor and prevent illegal trade in organs on one hand, and to protect the foreign medical tourists on the other hand. Indian medical regulation now prevents donation of organs such as kidney transplantation from strangers (except relatives). Because of this law, one of the patients from this study sample went to Sri-Lanka and did two-kidney transplants and thereafter she came to Thailand for further checkup under tourist-visa.

Tthe he government of Bangladesh is trying to provide universal primary healthcare to meet the MDG. However, to implement SDG-3, Bangladesh government has a long march, which is only possible with public-private partnerships (PPPs) with private and foreign healthcare providers investment in the domestic health sector. Social welfare needs are met slowly and it is important to consider equity and ethical issues gave a large number of poor people [50]. The government along with Bangladesh medical council should implement mandatory external international accreditation for the public and private hospitals of Bangladesh. Similar to India, domestic accreditation by National Accreditation Board for Hospitals and Healthcare Providers in Bangladesh should accredit and certify the qualifications of doctors, nurses, diagnostic centers, pathology, medical technologist, and other allied medical services to ensure quality in healthcare delivery. It helps to local patients to trust to the quality of the domestic healthcare system. Medical and non-medical professional staff should work sincerely, ethi- cally and honestly, by following the motto of service over and above selfish profit-motive objective, and reduce rampant corruption in public and private hospitals. Unless and until the current healthcare services are near international standards and accredited, free from corruption, Bangladeshi and also foreigners working and studying in Bangladesh (expatriates, students, and Bangladeshi diaspora) will not trust and have a poor perception of the quality of public and private healthcare in Bangladesh. Therefore, quality hospitals through PPFPs (pubic-Private-Foreign Partnerships), attracting foreign investment can be established [51], similar to JCI accredited super-specialty private Apollo Hospital in Dhaka. However, patients felt that quality and pricing for services of Apollo Hospital in Dhaka is below the standard of Apollo hospital of Chennai and Calcutta. Other famous private hospitals such as Sheikh Fazilatunnesa Mujib Memorial Specialized Hospital and Nursing College and Kwaja Yunus-Ali Medical College and Hospital should be accredited for quality and reviewed every three years by an international accrediting body like JCI. Strategic opportunities in the medical sector should be developed along with international health care management system and international health supporting networking system along with pharmaceuticals and logistic support to improve the quality of healthcare delivery in Bangladesh. The improved quality of healthcare delivery by international accreditation, and the elimination of corrupt practices in Bangladeshi healthcare will gradually reduce outbound medical travel by poor and middle class Bangladeshis, save medical travel costs, medical travel-risk and anxiety of being away from home and relatives, resulting in more and more Bangladeshi patients preferring to trust and use their healthcare system.

\section{Conclusions}

The findings conclude that four hypothesis listed in Table 2 were agreed. Unless Bangladesh improves its healthcare system, the outbound medical travel to Thailand and other neighboring countries will continue, nor it can dream of developing a medical tourism market to attract foreign patients. Doctors, nurses and lab technicians along with health management personnel must be ethical and corruption-free in order to meet the SDG of healthcare. Bangladesh should provide affordable quality of accessible and available universal primary and secondary healthcare and tertiary care for its poor and lower-middle-class patients in the public system, who cannot afford to travel cross-border and have to sell their fortune 
to do so. As a regulatory authority, Bangladesh Medical and Dental Council needs to play a dual role of accreditation of qualification and medical facilities for quality assurance and to ensure that medical treatment and facilities are of excellent quality $[1,21,55]$.

Bangladesh should have an international medical accrediting body to make sure that the quality of healthcare is provided without any corruption at the hospital and government level. Ranking of both public and private medical hospitals must be done to ensure continuous quality improvement. For future research, a qualitative and quantitative study of a large sample size will be undertaken of the Bangladeshi patients who had travelled to India, Thailand and Malaysia for medical treatment to identify the push and pull factors for cross-border medical tourism. The ways to have inclusive availability, affordability, access, equity and quality of healthcare services in Bangladesh should be identified. The role played by relatives who travel with the patient for medical treatment is also worth studying. Bangladesh should provide quality of accredited healthcare in both public and private hospitals aiming at the implementation of the inclusive provision of healthcare for all Bangladeshi and commitment from both the government and the medical profession, to reduce cross-border travel by poor and middle-class Bangladeshi and use more quality of domestic healthcare system.

\section{Acknowledgments}

The authors are grateful to Dr Aree Cheunwattana (Library and Information Science), Director of Library and Learning Center Dhurakij, Bangkok, Thailand for helping in data collection for the research.

\section{References}

1. Ali, M. M. (2012). Outbound Medical Tourism: The Case of Bangladesh. World Review of Business Research, 2(4), $50-70$.

2. Dutta, B. (2017, June 8). Why downsize allocation for health sector? The Financial Express. Retrieved from: https:// thefinancialexpress.com.bd/ (date of access: 25.07.2017).

3. Woodman, J. (2009). Patients beyond Borders: Thailand Edition, 1-171. Chapel Hill, NC: Healthy Travel Media.

4. Wongkit, M. \& McKercher, B. (2016). Desired Attributes of Medical Treatment and Medical Service Providers: A Case Study of Medical Tourism in Thailand. Journal of Travel \& Tourism Marketing, 33(1), 14-27.

5. Mannan, M. A. (2013, December). Access to Public Health Facilities in Bangladesh: A Study on Facility Utilisation and Burden of Treatment. Bangladesh Development Studies, XXXVI(4), 25-76.

6. Turner, L. (2013). Transnational medical travel: ethical dimensions of global healthcare. Cambridge Quarterly of Healthcare Ethic, 22(2), 170-180.

7. Connell, J. (2008). Tummy tucks and the Taj Mahal? Medical tourism and the globalization of health care. In Tourism Management, Analysis, Behaviour and Strategy. In: Woodside, A.G. and Martin, D. (Eds), 232-244. CABI: Oxford University Press.

8. Ormond, M. (2008). First World Treatments at Third World Prices: the real cost of medical tourism. In Medical tourism: Responding to the Cross-Border Pursuit of healthcare in Malaysia. In: R. Anand, \& S. Gupta (Eds), 69-77. Hyderabad: Icfai University Press.

9. Noree, T., Hanefelf, J. \& Smith, R. (2014). UK medical tourists in Thailand: they are not who you think they are. Globalisation and Health, 10(29), 1-7. Doi:10.1186/1744-8603-10-29.

10. Dasgupta, S. \& Dasgupta, S. D. (Eds.). (2014). Globalisation and Transnational Surrogacy in India: Outsourcing Life, 1-258. UK: Lexington Books.

11. Nwadiuko, J., James, J., Switzer, G. E. \& Stern, J. (2016). Giving Back: A mixed methods study of the contributions of US-Based Nigerian physicians to home country health system. Globalisation \&Health, 12(33), 1-8.

12. Ormond, M. \& Sulianti, D. (2014). More than medical tourism: lessons from Indonesia and Malaysia on South-South intra-regional medical travel. Current Issues in Tourism, 20(1), 94-110.

13. Cotton, M., Henry, J. A. \& Hasek, L. (2014). Value innovation: an important aspect of global surgical care. Globalisation and Health, 10(1), 1-5. Doi: 10.1186/1744-8603-10-1.

14. Medhekar, A., Wong, H. Y. \& Hall, J. (2014). Innovation in Medical Tourism Services Marketing: A case of India. In: A. Goyal (Ed.). Innovations in Services Marketing and Management: Strategies for Emerging Economies, Ch. 3, 49-66. USA: IGI Global.

15. Whittaker, A. (2015). Outsourced patients and their companions: Stories from forced medical travellers. An International Journal for Research Policy \& Practice, 10(4), 485-500.

16. Bookman, M. Z. \& Bookman, K. R. (2007). Medical Tourism in Developing Countries, 1-245. New York: Macmillan.

17. Medhekar, A. \& Ali, M. M. (2012). Key reasons for medical travel from Bangladesh to India. Conference paper presented at the Eighth IIDS-IIMS International Conference on Development. Bangkok, 16-19, December, 1-22.

18. Medhekar, A. \& Haq, F. (2015). Halal branding of Medical Tourism: Case of Indian Hospitals. In: H. Elgohary \& R. Eid (Eds). Islamic Tourism Trends, Challenges, and Opportunities in the Global Economy, Chapter 8, 160-189. USA: IGI Global. 
19. Wong, K., Velasamy, P. A. \& Tengku, N. T. (2014). Medical Tourism Destination SWOT Analysis: A Case Study of Malaysia, Thailand, Singapore and India. SHS Web of Conferences 12, 01037, EDP Sciences, 1-6. DOI: 10.1051/ C/ shsconf/20141201037.

20. Wongkit, M. \& McKercher, B. (2013). Towards a typology of medical tourists: A case study of Thailand. Tourism Management, (38), 4-12. 10.1016/j.tourman.2013.02.003.

21. Andaleeb, S., Siddiqui, N. \& Khandakar, S. (2007). Patient satisfaction with health services in Bangladesh. Health Policy \& Planning, 22(4), 263-273.

22. Ali, M., Chi, C. \& Núñez, M. A. (2017). Predictors of high out-of-pocket healthcare expenditure: an analysis using Bangladesh household income and expenditure survey, 2010 BMC Health Services Research, BMC series https://doi. org/10.1186/s12913-017-2047-0.

23. Mamun, M. Z. \& Andaleeb, S. S. (2013). Prospects and problems of emdical toruism in Banlgadesh. Internatinal Journal of Health Services, 43(1), 123-141.

24. Ali, M. M. \& Medhekar, A. (2016). Globalization, medical travel and healthcare management in Bangladesh. Problems and Perspectives in Management, 14(2-2), 362-372. Doi: 10.21511/ppm.

25. Zubayer, M. (2017). Measuring healthcare services quality in the private hospitals of Dhaka city, Bangladesh: An empirical study. British Journal of Marketing Studies, 5(1), 6-26.

26. Islam, Md. R. \& Farid, S. (2015). Negligence in Government Hospitals of Bangladesh: A Dangerous Trend. Journal of Social Sciences, 4(5), 12-18.

27. Chanda, R. (2002). Trade in Health Services. Bulletin of the World Health Organization, 80(2), 158-163.

28. Chanda, R. (2003). Social services and the GATS: key issues and concerns. World Development, 31(12), $1997-2011$.

29. Connell, J. (2006). Medical tourism, sea, sun, sand and surgery. Tourism Management, 27(6), 1093-1100.

30. Turner, L. (2010). Quality in health care and globalisation of health services: accreditation and regulatory oversight of medical tourism companies. International Journal of Quality in HealthCare, 23(1), 1-7. doi.org/10.1093/intqhc/mzq078.

31. Turner, L. (2007). First World Health Care at Third World Prices: Globalization, Bioethics and Medical Tourism. BioSocieties, 2(3), 303-325.

32. Lunt, N., Hardey, M. \& Mannion, R. (2010). Nip, Tuck and Click: Medical Tourism and the Emergence of Web-Based Health Information. The Open Medical Informatics Journal, 4(1), 1-11. Doi: 10.2174/1874431101004010001.

33. Pocock, N. S. \& Phua, K. H. (2011). Medical tourism and policy implications for health systems: A conceptual framework from a comparative study of Thailand, Singapore and Malaysia. Global Health, 7, 1-12. doi.org/10.1186/1744-86037-12.

34. Lunt, N., Machin, L., Green, S. \& Mannion, R. (2011). Are their implications for quality of care for patients who participate in international medical tourism? Expert Review of Pharmacoeconomics \& Outcomes Research, 11(2), $133-136$.

35. Connell, J. (2011). A new inequality? Privatisation, urban bias, migration and medical tourism. Asia Pacific Viewpoint, 52(3), 260-271.

36. Connell, J. (2013). Contemporary medical tourism: conceptualization, culture and commodification. Tourism Management, 34, 1-13. doi.org/10.1016/j.tourman.2012.05.009.

37. Hopkins, L., Labonté, R., Runnels, V. \& Packer, C. (2010). Medical tourism today: what is the state of existing knowledge? Journal of Public Health Policy, 31, 185-198.

38. Saniotis, A. (2007). International Ethics, Changing ethics in medical practice: a Thai perspective. Indian Journal of Medical Ethics, 4(1), 24-25.

39. Finch, S. (2014). Thailand top destination for medical tourists. Canadian Medical Association Journal, 186(1), E1-E2. Doi: $10.1503 /$ cmaj.109-4655.

40. Supakankunti, S. \& Herberholz, C. (2012). Transforming the ASEAN Economic Community (AEC) into a Global Services Hub: Enhancing the Competitiveness of the Health Services Sectors in Thailand. In: Tullao, T. S., \& Lim, H. H. (Eds). Developing ASEAN Economic Community (AEC) into a Global Services Hub, 147-171. Research Project Report 2011-1, Jakarta: ERIA.

41. Teh, I. (2007). Healthcare Tourism in Thailand: Pain ahead? Biotechnology in Malaysia and Thailand, 11(8), $493-497$.

42. Veerasoontorn, R., Beise-Zee, R. \& Sivayathorn, A. (2011). Service quality as a key driver of medical tourism: the case of Bumrungrad International Hospital in Thailand." International Journal of Leisure \&Tourism Marketing, 2, $140-158$.

43. Nutworadee, K. (2015). Motivation and Decision on Medical Tourism Service in Thailand. ASEAN Journal of Management \& Innovation, 2(2), 24-36.

44. Hossain, A. \& Lasker, S.P. (2010). Introduction of bioethics and its necessity in Bangladesh. Bangladesh Journal of Bioethics, 1(1), 2-18.

45. Cohen, E. (2008). Medical Tourism in Thailand. Assumption University-GSE e-Journal, 1(1), $24-37$.

46. Fukahori, H., Baba, Y., Hioki, F., Monkong, S., Intarasombat, P. \& Malathum, P. (2011). Healthcare services for Japanese elderly long staying in Thailand from the perspective of the patient and healthcare providers: A survey study. Gerontology and Geriatrics, 53(2), 168-173.

47. NaRanong, A. \& NaRanong, V. (2011). The effects of medical tourism: Thailand's experience. Bulletin of the World Health Organisation, 89, 336-344.

48. Rerkrujipimol, J. \& Assenov, I. (2011). Marketing strategies for promoting medical tourism in Thailand. Journal of Tourism, Hospitality \& Culinary Arts, 3(2), 95-105. 
49. Gursoy, D. \& McCleary, K. W. (2004). An integrative model of tourists' information search behaviour. Annals of Tourism Research, 31(2), 353-373.

50. Medhekar, A. (2014). Public-Private-Partnerships for inclusive development: Role of private corporate sector in provision of healthcare services. Procedia - Social \&Behavioral Sciences, 157, 33-44. https://doi.org/10.1016/j.sbspro.2014.11.007.

51. Chomvilailuk, R. \& Srisomyong, N. (2015). Three-dimensional perceptions of medical/health travellers and destination brand choices: cases of Thailand. Procedia - Social and Behavioral Sciences, 175(2), 376-383.

52. Medhekar, A. \& Newby, L. (2012). Information Search for Medical Treatment Abroad. Journal of Applied Global Research, 5(3), 53-72.

53. Pornphol, P. \& Naveevong, C. (2015). A Cloud-Based Management Information System for Medical and Wellness Tourism. International Journal of Innovation, Management and Technology, 6(6), 378-382.

54. Pathumporn, J. \& Suphan, K. (2016). Behaviours of Medical Tourists, who use medical tourism agencies in Thailand. International Business Management, 10(4), 512-516.

55. Moghavvemi, S., Ormond, M., Musa, G., Isa, R., Thirumoorthi, T., Mustapha, M., Kanapathy, K. \& Chandy, J. (2017). Connecting with prospective medical tourists online: A cross-sectional analysis of private hospital websites promoting medical tourism in India, Malaysia and Thailand. Tourism Management, 58, 154-163. DOI: 10.1016/j.

56. Whittaker, A. \& Chee, H. L. (2015). Perceptions of an international hospital' in Thailand by medical travel patient: Cross-cultural tensions in a transnational space. Social Science and Medicine, 124, 290-297.DOI: 10.1016/j. socscimed.2014.10.002.

57. Green, T., Green, H., Scandlyn, J. \& Kestler, A. (2009). Perceptions of short-term medical volunteer work: a qualitative Study in Guatemala. Globalization and Health, 5(4), 1-12./doi.org/10.1186/1744-8603-5-4.

58. Crush, J. \& Chikanda, A. (2015). South-South medical tourism and the quest for health in Southern Africa. Social Science \& Medicine, 124, 313-320. DOI: 10.1016/j.socscimed.2014.06.025.

59. Lajevardi, M. (2016). A Comprehensive Perspective on Medical Tourism Context and Create a Conceptual Framework. Journal of Tourism \& Hospitality, 5(5), 1-12. doi: 10.4172/2167-0269.1000236.

\section{Authors}

Muhammad Mahboob Ali - PhD in Economics, Professor, Dhaka School of Economics, University of Dhaka; Former Vice Chancellor, Presidency University (4/C, Easkaton; Ramna; Dhaka, 1000 Bangladesh; e-mail: pipulbd@gmail.com,mahboobalidsce@gmail.com).

Anita Medhekar - Master of Economics, PhD (Researcher), Senior Lecturer in Economics, School of Business and Law, Central Queensland University (Building 34/2.13, Off Bruce Highway, 4702, Rockhampton, 443256, Australia; e-mail: a.medhekar@cqu.edu.au). 